\title{
Una Escritura Revolucionaria
}

Desde hace unos diez años las letras hispanoamericanas han pasado al primer plano de la consideración crítica. Una literatura semi-colonial - marginalizada por el subdesarrollo de un continente aún en manos de capitales extranjeros - se ha convertido en menos de una década en una de las literaturas centrales de esta época. Este fenómeno de expansión (que industrialmente se conoce con el nombre onomatopéyico de boom) se ha concentrado naturalmente en la novela: género más accesible aunque, por la manera experimental como lo trabajan los hispanoamericanos, no tan popular como parece. En todas partes se traduce ahora la ficción de Borges (maestro indiscutido de los nuevos novelistas), se multiplican las ediciones extranjeras de Julio Cortázar, Carlos Fuentes, Gabriel García Márquez, Guillermo Cabrera Infante y Mario Vargas Llosa. Escritores más secretos o esotéricos (como Juan Carlos Onetti o José Lezama Lima) comparten con los más jóvenes el interés de los editores extranjeros. Así han salido recientemente, o están por salir, versiones francesas, inglesas - italianas, de Boquitas pintadas, de Manuel Puig y De donde son los cantantes, de Severo Sarduy, así como de Juntacadáveres, de Onetti, o Paradiso, de Lezama Lima.

Este movimiento editorial tiene sus raíces en la notable expansión de las editoriales hispanoamericanas durante la última década, y también en la política promocional, muy hábil, de ciertos semanarios hispanoamericanos de gran circulación, que son los verdaderós fabricantes del boom. Porque antes de ser descubierta en Europa o en los Estados Unidos, la nueva novela hispanoamericana fue descubierta en la América hispánica. Fueron los lectores de México los primeros en reconocer a Juan Rulfo, como los de Montevideo fueron los que saludaton a Martínez Moreno, y los de Santiago de Chile los que consagraron a José Donoso. El éxito internacional vino después. $\mathrm{Y}$ cuando ocurrió, pudo apoyarse no sólo en la obra producida por los novelistas de la última década, sino en toda una literatura que a lo largo de varias generaciones 
ya habia producido no sólo una novela importante, sino un ensayo de primer orden y una poesía que cuenta entre las primeras de este siglo.

\section{HACIA EL NUEVO HOMBRE AMERICANO}

Aunque el proceso de expansión de las letras hispanoamericanas se ha acelerado notablemente en los últimos diez años, es evidente que las señales del cambio ya eran visibles (para algunos, al menos) en la tercera década de este siglo. Y tal vez aún antes. Por eso, para poder entender lo que está ocurriendo ahora conviene echar una mirada a las etapas principales de difusión de la literatura hispanoamericana en el mundo actual.

La emergencia súbita de la nueva novela hispanoamericana en las letras europeas y norteamericanas está indudablemente vinculada a los acontecimientos políticos más destacados de la última década: la presencia cada día mayor de los países del Tercer Mundo en la conciencia de occidente; el impacto en América Latina de la revolución cubana; las actividades de la guerrilla urbana en tantas partes del mundo, y en particular en nuestra América. Pero creer (como proponen almas cándidas) que sólo estamos viendo las consecuencias culturales de una revolución política es creer que la literatura está determinada exclusivamente por los cambios ocurridos en la sociedad. Lo que ahora llamamos la nueva novela hispanoamericana es el resultado de un largo y penoso proceso. Cubre varias décadas, aunque se precipita en la última, y ha permitido establecer ya lo que Octavio Paz ha llamado en uno de sus ensayos, "la tradición de la ruptura": una profunda continuidad que es periódicamente destruída y lestaurada por nuevos experimentos.

No hay que olvidar que ya a fines de los años veinte y comienzos de los treinta, los mejores narradores hispanoamericanos fueron descubiertos, publicados y elogiados críticamente por los espalnoles. Algunos de los más importantes escritores de ese período, como el uruguayo Horacio Quiroga, los mexicanos Mariano Azuela y Martín Luis Guzmán, el colombiano José Eustasio Rivera, el venezolano Rómulo Gallegos y el argentino Ricardo Güiraldes, vieron sus obras publicadas en España por editoriales que las distribuian en todo el mundo de habla hispánica. En aquella época, España tenía muy pocos novelistas que pudieran compararse con aquéllos en habilidad narrativa, pasión y compromiso político. Aunque en su mayor parte la narrativa de estos escritores hispanoamericanos era una exploración del mundo exterior o un exaltado proyecto utópico, la mejor 
obra por ellos producida (Los desterradas, de Quiroga; El águila y la serpiente, de Guzmán) también contenía una visión mitopoética de algunas escondidas realidades del Nuevo Mundo. En cierto sentido, esta obra establecía un vínculo invisible con los relatos de las primeras exploraciones y descubrimientos que introdujeron América al lector europeo.

La mayor debilidad de este tipo de narrativa residia en la presentación de los conflictos internos de sus personajes. En la obra de los más famosos novelistas de los años veinte y treinta, el paisaje americano y la naturaleza bravía de tal modo dominaban al hombre, tanto lo moldeaban o aplastaban, que el individuo casi desaparecía, o quedaba reducido (como Doña Bárbara, Don Segundo Sombra, o Demetrio Macías en Los de abajo) a la condición de arquetipo: un símbolo de algo, no un personaje. La presentación de los conflictos humanos resultaba generalizada; las pasiones asumian el color anónimo de la mayoría. Fuerzas económicas y sociales de naturaleza abstracta -en particular: el poder político y las aspiraciones de la clase dirigente- se oponían, digamos, a los desheredados y oprimidos de los Andes, de la selva amazónica, de las pampas argentinas. El individuo quedaba reducido a una cifra en el hostil universo. La geografia lo era todo, el hombre nada. En cambio, para los nuevos novelistas que América hispánica ha estado produciendo en las últimas décadas, el centro de gravedad ha cambiado radicalmente-desde un paisaje creado por Dios a un paisaje urbano, creado y habitado por el hombre. Las pampas y la cordillera han cedido el paso a la gran ciudad. En tanto que los viejos novelistas seguiąn considerando a la ciudad sólo como una presencia remota, arbitraria y misteriosa, para estos nuevos escritores la ciudad es el eje, el lugar al que los protagonistas de la nueva novela son atraídos irresistiblemente. La visión algo despersonalizada de los años veinte y treinta ha vuelto a adquirir carne y hueso. Súbitamente, seres novelescos poderosos y complejos están emergiendo de las masas anónimas de las grandes ciudades americanas.

Este cambio dramático - que corresponde sociológicamente al enorme crecimiento de las ciudades, pero también refleja la influencia cada vez mayor del psicoanálisis y el existencialismo- tampoco ha dejado intacta la visión de los novelistas que siguen preocupados con los temas rurales. Aunque éstos continúen a registrar; en la superficie, la lucha tradicional del hombre contra la naturaleza, los personajes que ahora presentan ya no son abstracciones, cifras que justificarían un enfoque predominantemente político o sociológico. Son personajes complejos y ambiguos que "parecen" seres humanos completos. 
Hemos terminado ya con todas esas épicas de campesinos y gauchos -con su caracterización bidimensional, su estructura "documental", tan mecánica y abstracta. Son las ciudades las que ahora monopolizan la atención de los novelistas más jóvenes. Y cuando éstos vuelven su aten. ción al paisaje es para revelar mejor el lado mítico del hombre hispanoamericano. Los nuevos novelistas combinan, por eso, una sensibilidad aguda para todo lo político y social, con una notable sutileza narrativa, un compromiso personal con una imaginación que les permite asediar otras dimensiones trascendentales de la realidad. Una nueva concepción del hombre está emergiendo del caos y de la explotación económica, de los golpes de estado y el subdesarrollo, de las "revoluciones" militares y la guerrilla urbana. Los nuevos novelistas son (lo quieran o no) los profetas de este nuevo hombre.

\section{UNA NUEVA LENGUA HISPÁNICA}

La primera emergencia de la narrativa hispanoamericana en España durante los años treinta fue muy breve. $\mathrm{La}$ guerra civil detuvo casi por completo esta difusión excepcional, después de 1936; la segunda guerra mundial dio el último golpe mortal al proceso. Durante dos décadas, por lo menos, el tráfico de libros entre España y América hispánica fue modificado por la victoria de Franco. Algunos libros hispanoamericanos (los que pasaban la censura española) seguían siendo publicados en la península, y circulaban por el Nuevo Mundo en ediciones españolas. Ciertos (no todos) libros hispanoamericanos podían circular en España. Pero sólo en esta última década la censura se ha reducido lo suficiente allí como para permitir que casi toda la narrativa hispanoamericana sea publicada o distribuida sin mayores tropiezos. Algunas excepciones notables (como 1a prohibición total de Cambio de piel, de Carlos Fuentes) ha permitido poner a prueba la censura misma.

Tal vez el momento decisivo de la emergencia internacional de la narrativa hispanoamericana sea aquel día del año 1961 en que, reunidos en 1a isla de Formentor algunos de los editores europeos y norteamericanos de vanguardia deciden repartir el recién creado premio internacional entre el escritor franco-irlandés Samuel Beckett, uno de los clásicos del siglo, y el aún desconocido Jorge Luis Borges. A partir de ese premio y de la traducción posterior de una antología de sus ficciones, publicada simultáneamente en varios idiomas bajo el título tan significativo de Laberintos, Borges habrá de ser aceptado poco a poco como uno de los creadores más 
singulares de hoy. Su nombre pasa a ser mencionado por los especialistas junto a los de Joyce, Kafka y Nabokov. Pronto los novelistas objetivos franceses (como Robbe-Grillet) se apoyarían en sus ficciones y en sus teorías para desarrollar sus propias búsquedas; ciertos críticos estructuralistas (como Genette y Ricardou) disecarían sus relatos mientras que en los Estados Unidos algunos jóvenes narradores (como Thomas Pynchon y Donald Barthelme) harian literatura visiblemente borgiana.

Pero si bien el caso de Borges es singular, no es único. En mayor o menor grado, algunos de los poetas. hispanoamericanos más importantes están siendo ahora leídos y traducidos, comentados, discutidos e imitados por la gente más joven. En los Estados Unidos la poesía reciente cuenta a Vallejo, a Neruda, a Octavio Paz y a Nicanor Parra entre sus maestros. El interés por Huidobio empieza ya a manifestarse. En Europa se lee y traduce en ediciones cada vez más cuidadas la poesía hispanoamericana. En todas partes se multiplican las antologías y los estudios críticos.

Para buscar las raíces de este triunfo de la poesía hispanoamericana hay que remontarse a los finales del siglo xix. Ya en 1898, cuando daba fin a su ensayo sobre la obra de Rubén Darío, el entonces joven crítico uruguayo José Enrique Rodó aludía al viaje del poeta a España y anunciaba el triunfo que aquélla habría de alcanzar en la misma Madre Patria. Unos dieciocho años más tarde, Rodó volvería a evocar ese viaje al escribir un artículo a la muerte de Dario. Apoyándose entonces en una feliz imagen del novelista venezolano Manuel Díaz Rodríguez sobre el "retorno de las carabelas", afirmaría Rodó en 1917: "Por él [Darío] la ruta de los conquistadores se tornaría del ocaso al naciente".

En efecto: el viaje de Darío a España en las postrimerías del siglo xIx marca la línea divisoria de las aguas, ese momento en que las letras de la América hispánica devolverian con intereses la visita de las carabelas, llevando esta vez en su vientre no sólo el oro de Indias sino el otro metal, aún más perdurable, de la nueva lengua española de esta América, de la nueva poesía, de la nueva prosa. Porque Darío llegó a España como pacífico reconquistador y alli, rodeado por los más jóvenes poetas como Antonio Machado y Valle Inclán, contribuyó definitivamente a enterrar la poesía y la prosa decimonónica de una literatura carcomida ya por la polilla, ahogada por el floripondio, esclerosada en el discurso retumbante. Con Darío viajaban otros poetas y prosistas hispanoamericanos que no habían podido hacer el viaje: Julián del Casal y José Asunción Silva, los dos exquisitos y perversos; Salvador Díaz Mirón y Francisco Gavidia; Manuel González Prada y Manuel Gutiérrez Nájera, y hasta los más jóvenes como Leopoldo Lugones, el cordobés. Pero viajaba sobre 
todo el maestro de Darío, ese José Martí que en prosa y verso había cambiado radicalmente el rumbo del español de América. El impacto de Darío y los modernistas americanos resultó perdurable. Poco después, Ariel, el discurso hispánico que Rodó publica en 1900, habría de ampliar aún más el dominio de la lengua del Nuevo Mundo. Aquí empezó la transformación segura de una literatura dispersa, colonial hasta en su independencia, en una literatura universal. El triunfo de Darío y de Rodó en España es el primer paso. Pero todavía las letras de Amética no habían salido del área del idioma: todavía no habían sido reconocidas en el resto de Europa. Una inevitable reacción nacionalista en la misma España, que ha querido oponer el 98 al Modernismo, como si se tratara de dos movimientos contradictorios y no (como en realidad son) complemen. tarios, habría de intentar reducir esta primera salida de los indianos, ese primer retorno pacífico de las carabelas, a una experiencia de frivolidad. Pero el intento es inútil. Porque los indianos habrian de volver, una y otra vez.

\section{Ee ESCÁNDALO DE LA NUEVA POEŚ́A}

La segunda salida (menos visible pero no menos importante) ocurre poco después de la muerte de Darío, seguida un año más tarde por la de Rodó. Esta salida se prolonga hasta los años treinta, hasta el estallido de la guerra civil española. Es el momento de las vanguardias en toda Europa, y a una España todavía sumisa a los' idolos del 98, todavía envuelta en ciertas prolongaciones exquisitas del Modernismo, llegan los poetas hispanoamericanos. Llega, por ejemplo, Vicente Huidobro, el chileno que venía desde su lejana tierra austral por la ruta compleja de Buenos Aires y París. Lo que trae Huidobro a España es (nada menos) que la vanguardia entera. Su creacionismo estalla como un escándalo en los cenáculos de los jóvenes; alli orienta a Gerardo Diego, a Juan Larrea, a Guillermo de Torre, hacia formas más nuevas y audaces de poesía; inspira incluso al maestro Rafael Cansinos Assens a convertirse en jefe de un movimiento, y viene a sumarse a los esfuerzos (hasta entonces poco comprendidos) del gran Ramón Gómez de la Serna. Como consecuencia de esa conmoción pronto nacerá en España el ultraísmo, movimiento de vanguardia en que colaborará el joven Jorge Luis Borges, recién llegado a España de una larga temporada de estudios en la Suiza neutral y expresionista de la primera guerra.

Con el retorno posterior de Huidobro y Borges a la América del Sur, y la participación conjunta de ambos en la compilación de un Indice de 
Ia nueva peesía americana que organiza Alberto Hidalgo en 1926, la vanguardia se difunde en nuestro continente. Mientras en España el ultratsmo tendría corta vida y se iría disolviendo en movimientos más tradicionales, como el retorno a Góngora y al barroco formal (no al agónico), en Argentina, en México y en Chile, la misma fuerza engendrará importantes movimientos como el ultraísmo argentino (más metafísico y clásico que el español), el estridentismo mexicano, el superrrealismo chileno, de larga y activa trayectoria. De esos experimentos, y de los que estaban llevando a cabo en el Perú César Vallejo y César Moro, saldría en el curso de los años veinte y treinta toda la poesía que importa: Altazor, de Huidobro, Trilce y los Poemar humanos, de Vallejo, la Residencia en la tierra, de Neruda, la primera colección de Poemas, de Borges. España no queda al margen de esta renovación. Otra vez, el viaje de un poeta hispanoamericano habrá de hacer estallar hacia 1935 un núcleo de poesía en la Madre Patria. Esta vez el viajero se llama Pablo Neruda. En Madrid, rodeado de García Lorca y Rafael Alberti, de Vicente Aleixandre y Manuel Altolaguirre, y sobre todo del joven pastor, Miguel Hernández, que él descubre y apoya, Neruda proclamará en su revista Caballo verde para la poesía, la necesidad de una poesía sin pureza, una poesía de todos los días, una poesía para todos los hombres, que habrá de oponer a la poesía excesivamente pura de Juan Ramón Jiménez y sus epígonos. En sus versos y en sus manifiestos, Neruda defenderá una poesía carnal y enfurecida, una poesía revolucionaria. Es cierto que esta renovación, apenas iniciada, que pudo haber cambiado por completo el curso de la poesia lírica en todo el ámbito de la lengua, fue interrumpida brutalmente por la guerra civil. Durante algunos trágicos meses, sin embargo, el milagro de la nueva poesía pareció darse en la tierra de España, cuando al lado de los grandes poetas españoles estuvieron allí el joven Octavio Paz y el moribundo Vallejo, Gabriela Mistral y Raúl González Tuñón, Vicente Huidobro y Pablo Neruda. De ese instante luminoso aún perduran España, aparta de mí este cáliz, de Vallejo, y España en el corazón, de Neruda. Pero la muerte y la dispersión, el asesinato y el duro exilio liquidaton el resto. Habria que esperar a los años sesenta para que se produjera la tercera salida de las letras hispanoamericanas.

\section{EL RECONOCIMIENTO DE LA NUEVA NARRATIVA}

Ya se ha visto que el año 1961, con el premio de los editores internacionales a Borges, marca una fecha inicial. A partir de esa fecha, la 
difusión de la nueva narrativa es cada día mayor. En España, el éxito de la novela hispanoamericana es total. El Premio Biblioteca Breve de la importante editorial barcelonesa Seix-Barral es concedido abrumadoramente, casi todos los años, a novelistas hispanoamericanos. El peruano Mario Vargas Llosa lo obtiene en 1962 con La ciudad y los perros; en 1963 le corresponde al mexicano Vicente Leñero por Los albañiles; en 1964 al cubano Guillermo Cabrera Infante por Tres tristes tigres; en 1967 al mexicano Carlos Fuentes por Cambio de piel; en 1968 al venezolano Adriano González León por País portátit; en 1969 al chileno José Donoso por El obsceno pájaro de la noche. Las ediciones de novelistas de esta América se multiplican en Madrid y en Barcelona; incluso algunos de los escritores españoles más importantes, como el novelista Juan Goytisolo, el poeta Félix Grande o el crítico José María Castellet, no vacilan en reconocer el valor singular de las letras hispanoamericanas.

En el resto del mundo se repite, a escala, esta difusión. El Premio Nobel de Literatura otorgado a Miguel Angel Asturias en 1967 no hizo sino objetivar el interés europeo por una narrativa que abarca el occidente entero. Si en Italia, Sobre béroes y tumbas, de Ernesto Sábato, se convierte en best-seller y suscita apasionados comentarios, en Estados Unidos, el éxito de Cien años de soledad, de García Márquez, en su primera edición de 1969, se amplía y confirma en 1971 al convertirse ahora en paper-back. Estos son apenas algunos ejemplos. Otros aspectos singulares de la curiosidad e interés que despierta hoy la literatura hispanoamericana podrían también citarse. Mientras los cuentos de Cortázar inspiran a Michelangelo Antonioni su mejor película reciente, Blow-Up, o sirven de punto de partida a una de las más feroces sátiras de Jean-Luc Godard, en Week-End, los textos de Borges inspiran al mismo director francés en Alphaville, al italiano Bernardo Bertolucci que transforma "El tema del traidor y del héroe" en una película política (The Spider's Stratagem) y hasta al cantante Mick Jagger que en Performance aparece leyendo la edición inglesa de la Antología personal del maestro argentino. En Francia, mientras La traición de Rita Hayworth, de Manuel Puig, encabeza la lista de las mejores traducciones del año 1969, según Le Monde, la versión de Tres aristes tigres, publicada por Gallimard obtiene en 1971 el premio al mejor libro extranjero. ¿A qué seguir?

\section{LA REVOLUCTÓN TOTAL DEL LENGUAJE}

La tercera salida de las letras hispanoamericanas ha servido, sobre todo, para demostrar la vitalidad inesperada de un continente marcado 
desde sus orígenes por la destrucción y la muerte, por el expolio sistemático de sus riquezas y el genocidio, la opresión y la injusticia colonial. Pero, también, señalado desde su nacimiento por las más fabulosas utopías, por la ambición de hazañas imposibles, por el espíritu de incesante revolución, por el esplendor de una lengua que tiene vocación universal. La vitalidad de la América hispánica es la vitalidad de un pueblo de múltiples orígenes, encrucijada viva de razas y sangres, de lenguas y culturas, creador de un mestizaje cultural que se centra en el Nuevo. Mundo peto se proyecta radicalmente fuera. En este momento en que los imperios centrales (Estados Unidos, la Unión Soviética, Europa como. unidad a pesar de sus divisiones parroquiales), se ven cada vez más cercados por la marea humana de la periferia, América hispánica tiene ya: una lengua y una literatura que han llegado a la madurez. En esa lengua, los hombres de este continente están creando una nueva literatura que aprovecha lo mejor de las tradiciones de los imperios centrales y que trans. forma ese aporte por medio de un inesperado proceso de mestización, por una incesante libertad creadora, por el impulso más profundamente revolucionario que ha conocido este tiempo: el de la revolución total de. la lengua.

Por lengua no me refiero exclusivamente al uso de ciertas formas, colectivas del habla. En términos estrictamente literarios, lenguaje no es sinónimo del sistema general de la lengua en un idioma determinado, sino sinónimo de una cierta habla de un cierto género o escritor. En este sentido, el lenguaje de la nueva novela hispanoamericana (por ejemplo) está formado básicamente no sólo de la expresión de una realidad profunda que han elaborado, a partir de Borges y Asturias, tantos escritores notables, sino también de la expresión profunda que esa misma lengua ha encontrado en la obra de poetas y ensayistas. El leguaje de la nueva novela se apoya tanto en Cortázar como en Paz, en Onettı como en Parra, en Carpentier como en Lezama Lima (el poeta antes que el narrador). Lo mismo podría decirse de la obra ensayística de Alfonso Reyes: y José Carlos Mariátegui, de Pedro Henríquez Ureña y Ezequiel Martínez Estrada, de Borges y Paz. Es, sin duda, debido a este fondo común. que la nueva novela no sólo es hoy el más completo objeto poético para la exploración de la realidad, sino también el más rico instrumento para: trasmitir esa otra realidad paralela: la realidad del lenguaje.

Apoyándose simultáneamente en el francés y el italiano, contaminanclo todo de anglicismos y norteamericanismos, corrompiendo las academias de la lengua y las escuclas de la retórica (vieja o nueva) de Europa, la nueva literatura hispanoamericana entra a saco con el español, lo tuerce: 
y lo retuerce, lo transforma y metamorfosea para escribir como no se había hecho antes en ningún pais del orbe hispánico. Así, Borges, con ayuda de Bioy Casares, reinventa y parodia el "lunfardo" porteño en los cuentos de "Bustos Domecq" y su discípulo, "B. Suárez Lynch", mientras Neruda suelta el verso de sus Residencias y Vallejo el de su Trilce. A los experimentos de Octavio Paz en Blanco y Nicanor Parra en sus Artefactos corresponden los de César Fernández Moreno en los Aeropuertos o los de Homero Aridjis en Perséfone (falsa novela) o en Los espacios azules (verdadera poesía). En la narrativa, Rayuela, de Cortázar, inaugura en 1963 una serie experimental que se continúa con Tres tristes tigres, Cambio de piel, Paradiso, El obsceno pajaro de la noche. Más cerca aún, Severo Sarduy en De donde son los cantantes y en la aún inédita, Cobra, Manuel Puig en Boquitas pintadas, o Reynaldo Arenas en $E l$ mundo alucinante (que da vueltas, como un guante, a las Memorias de Fray Servando Teresa de Mier, para mostrar su envés delirante), son otros tantos experimentos que llevan la parodia hasta extremos inéditos.

Nunca ninguna literatura ha producido tantos escritores verdadera. mente revolucionarios en un plazo tan breve. Insisto: revolucionarios en el sentido más estricto de la palabra. Escritores que quizá nunca habrán de tomar en sus manos la metralleta o el cocktail Molotov pero que no dejan de tomar la palabra y la usan con letal eficacia. En ellos, el idioma deja de ser lo que fue durante mucho tiempo, un lujo de pocos, vigilado celosamente por quienes se creían sus dueños por haber nacido en algún privilegiado lugar del mundo, para convertirse en la caudalosa expresión de un continente entero: una babel de voces hispánicas que modulan la voz única de la lengua.

En poco más de medio siglo, en el lapso que corre desde el viaje de Darío a España en 1898 y el Premio Formentor concedido a Borges en 1961, la literatura hispanoamericana ha dado ese salto enorme, abando. nando la marginalización en que parecía irremediablemente situada por las fuerzas políticas y económicas, para instalarse en el centro de las letras de hoy. Lo que parecía impasible hace cincuenta, cuarenta, incluso treinta años, es ahora un hecho. Verificarlo es también una forma de celebrarlo.

Yale University. 